\title{
Selective byssus attachment behavior of mytilid mussels from hard- and soft- bottom coastal systems
}

\author{
Moisés A. Aguilera ${ }^{\mathrm{a}, \mathrm{b}, *}$, Martin Thiel ${ }^{\mathrm{a}, \mathrm{b}, \mathrm{c}}$, Niklas Ullrich $^{\mathrm{d}}$, Guillermo Luna-Jorquera ${ }^{\mathrm{a}, \mathrm{b}, \mathrm{c}}$, \\ Christian Buschbaum ${ }^{\mathrm{e}}$ \\ a Departamento de Biología Marina, Facultad Ciencias del Mar, Universidad Católica del Norte, Larrondo 1281, Coquimbo, Chile \\ b Center for Advanced Studies in Arid Zones, CEAZA, Coquimbo, Chile \\ ${ }^{c}$ Millennium Nucleus Ecology and Sustainable Management of Oceanic Island (ESMOI), Coquimbo, Chile \\ ${ }^{\mathrm{d}}$ Universität Kiel, Zoologisches Institut, Arbeitsgruppe Marine Ökologie und Systematik, Olshausenstr. 40-60, D-24118 Kiel, Germany \\ e Alfred Wegener Institute, Helmholtz Centre for Polar and Marine Research, Wadden Sea Station Sylt, Hafenstrasse 43, 25992 List/Sylt, Germany
}

\section{A R T I C L E I N F O}

\section{Keywords:}

Attachment strength

Byssus production

Mytilid mussels

Selective behavior

Substratum choice

\begin{abstract}
A B S T R A C T
In both sedimentary and rocky coastal habitats, epibenthic mytilid mussels use byssal threads for attachment to the substratum and to form beds with high densities of individuals. Number and attachment strength of byssal threads can be adjusted according to external factors such as hydrodynamic forces or predators, but it is unknown whether mytilid mussels distinguish between substrata of different quality for byssus attachment in different habitat types. In field studies, we examined the attachment strength of the mussel Perumytilus purpuratus growing on Pacific hard- and soft-bottom shores in Chile and of the blue mussel Mytilus edulis from an Atlantic rocky shore in France and a sedimentary shore in the North Sea (Germany), respectively. In additional laboratory experiments, we studied mussel substratum selectivity of both bivalve species from soft and hard bottoms by offering living versus dead, barnacle-fouled vs. unfouled, and firmly attached vs. loose conspecifics. In the field, attachment strength of $P$. purpuratus on hard bottoms was substantially higher than on soft bottoms even though mussels produced more byssus in the latter habitat. In contrast, blue mussels $M$. edulis showed only a slightly reduced attachment strength on soft compared to hard bottoms. In the soft-bottom habitat, fouled individuals from the edge of a blue mussel bed were especially strongly attached. In the byssus attachment behavior experiments, $P$. purpuratus from both habitats showed a significant preference for living conspecifics and those from soft bottoms preferred firmly attached conspecifics. Blue mussels had no preference for particular conspecifics except those from soft-bottom habitats, which preferred fouled over clean mussels. In general, in the choice experiments hard-bottom $M$. edulis produced more byssus. Our results confirmed that mytilid mussels may show active substratum choice for byssus attachment, which depends on mussel species and habitat type. The results suggest that mussels are adapted to a particular habitat type, with $P$. purpuratus showing lower adaptation to soft-bottom areas while $M$. edulis shows successful strategies for both environments.
\end{abstract}

\section{Introduction}

One major determinant for population dynamics and the survival potential of marine species in both rocky and soft-bottom coastal habitats is their ability to resist biotic and abiotic stressors such as predation and dislodgment by waves (e.g. Reise, 1985; Denny and Gaylord, 2010). Especially, strong hydrodynamic forces can pose a challenge for benthic invertebrate species, which might need to adjust their body size, morphology and also their behavior to persist (e.g. Helmuth et al., 2006). Thus, coastal organisms have evolved a suite of strategies to cope with environmental conditions and habitat quality (e.g. substratum types) to ensure survival and persistence (e.g. Wethey, 2002; Harley, 2008). Knowledge of strategies used by benthic individuals to resist stressful conditions is thus essential to understand the ability of species to occur within a habitat and to expand their geographic ranges. Additionally, natural removal of sessile and semi-sessile habitat-forming organisms (e.g. bivalves, corals, sponges, or kelps) by hydrodynamic forces has a controlling influence on community structure in intertidal habitats (Levin and Paine, 1974; Paine and Levin, 1981). Consequently, how different ecosystem engineers can cope with predominant environmental conditions is also crucial for the occurrence and dynamics of their associated organisms.

\footnotetext{
* Corresponding author at: Departamento de Biología Marina, Facultad Ciencias del Mar, Universidad Católica del Norte, Larrondo 1281, Coquimbo, Chile.

E-mail address: moises.aguilera@ucn.cl (M.A. Aguilera).
} 
Ecosystem-engineering organisms including byssus thread producing mussels colonize coastal systems characterized by stressful conditions (such as strong hydrodynamic forces), because they have different adaptive attachment strategies allowing persistence and recovery (Levin and Paine, 1974; Carrington et al., 2009; and see Carrington et al., 2015 for review). Increasing hydrodynamics enhance the risk of dislodgment (Witman and Suchanek, 1984), which decreases with mussel attachment strength (e.g. Carrington, 2002a; Carrington et al., 2008). It is known that mussels can adapt their attachment strength by means of increased byssus production (Denny and Gaylord, 2010; Carrington et al., 2015), which depends on mussel size, with small-sized individuals typically producing more byssus threads than large-sized conspecifics (e.g. Babarro and Carrington, 2013). While mussels might also adjust the thickness of byssus in response to hydrodynamic variability (Carrington et al., 2015), they mostly enhance or decrease the number of byssus threads (Carrington et al., 2008; Babarro and Carrington, 2013).

The ability to attach byssal threads to the substratum and to form dense aggregations has permitted mussels to colonize both hard- and soft-bottom habitats, where they can attach to each other because little suitable attachment substratum is available (see for example Young, 1983a; Berkman et al., 1998; Buschbaum, 2000). Specifically, reciprocal byssus attachment between conspecifics results in dense aggregations of individuals (Okamura, 1986a; Alvarado and Castilla, 1996) in which the position of an individual seems to be important for dislodgement risk since individuals in the center may be better protected from drag forces than bivalves at the edge of a mussel bed (Witman and Suchanek, 1984; Okamura, 1986b; Bell and Gosline, 1997; wa Kangeri et al., 2014). Thus, predictable conspecific signals can be critical for survival and individual persistence through firm attachment in different habitats. Specifically, shells of recently dead mussels, for example, are common in mussel beds (Buschbaum, 2001; Gutiérrez et al., 2003), yet they do not offer the same hold as shells of living conspecifics. Similarly, neighboring conspecifics that are firmly fastened to the substratum can be important for attachment strength of an individual. Furthermore, epibenthic molluscs are frequently overgrown by epibionts, which may influence their performance at various levels, e.g. by increasing hydrodynamic forces for an overgrown individual (e.g. see Laudien and Wahl, 1999; Buschbaum and Saier, 2001; Buschbaum et al., 2016). Therefore, mussels seeking byssus attachment sites may prefer clean conspecifics.

Thus, some conspecifics could offer a better hold than others (e.g. live $>$ dead, clean $>$ fouled, firmly attached $>$ loose), and the question arises whether mussels seeking attachment sites are able to distinguish between individuals and substrata of different quality. Recent studies conducted in soft-bottom habitats showed that $M$. edulis attach byssus threads primarily to large shell fragments rather than on living conspecifics, depending on levels of hydrodynamic disturbance (wa Kangeri et al., 2014). Similarly, sheltered mussels seem to invest less in byssus threads than edge-positioned (or wave-exposed) individuals (e.g. Cheung et al., 2009; wa Kangeri et al., 2016). Indeed, these findings indicate that blue mussels are capable of distinguishing between different substratum types (e.g. Khalaman and Lezin, 2015) and also suggest high plasticity in adhesion strategies of individuals within the mussel matrix. However, it is not known whether byssus placement on conspecifics is selective in mytilid mussels and how habitat predictability for attachment substratum (hard versus soft bottoms) could influence selectivity.

Based on these considerations, we examined the following specific questions, which guide the present study: (i) Is mussel attachment strength influenced interactively by size, epibiont load and mussel position within the bed matrix? (ii) Do mussels selectively attach byssus to particular conspecifics? (iii) Can habitat (substratum) predictability for attachment influence selectivity? Consequently, the main goal of our study was to examine attachment strength, and selective byssal attachment to conspecifics in two mytilid species, namely the purple mussel Perumytilus purpuratus and the blue mussel Mytilus edulis. Both species occur in both hard- and soft-bottom habitats and we studied interspecific and habitat-specific differences in attachment strength and selective byssus attachment. In field surveys, we investigated whether attachment strength or dislodgement risk of mussels is related to shell size, position of individuals within the mussel matrix, presence of barnacle epibionts, and habitat type. We specifically examined interactive effects as position (edge versus center) and epibiont presence (clean versus barnacle-fouled) could influence the expected linear relationship between size and attachment strength of individual mussels.

In controlled laboratory experiments we examined whether mussels are selective with respect to conspecifics for byssus attachment, and whether individual choice varies with habitat type (i.e. soft versus hard bottom). Thus the general hypothesis was that mytilid mussels, when offered a choice, show selectivity by attaching their byssus threads to shells of better suited conspecifics as an adaptive strategy to enhance survival. We tested whether mussels attach byssus preferentially to living instead of dead conspecifics, clean instead of fouled individuals, firmly attached instead of lose mussels.

\section{Material and methods}

\subsection{Study sites and study species}

The purple mussel Perumytilus purpuratus is dominant at mid to high rocky intertidal levels from Peru to southern Chile (Prado and Castilla, 2006), with marked connectivity patterns across the SE Pacific coast (Guiñez et al., 2016). The blue mussel Mytilus edulis is common on soft bottoms along the northern Atlantic, and $\mathrm{N}$ and $\mathrm{S}$ Pacific coasts (Molen et al., 2012).

Purple mussels were examined at two different locations in Chile (Totoralillo and Puerto Montt, Fig. 1a and b), and blue mussels were studied at two different sites in NW Europe (Concarneau, France; Sylt, Germany, see Fig. 1c and d). At all sites mussels occur in dense patches of many aggregated individuals (see Fig. 2).

Purple mussels $P$. purpuratus from hard-bottom habitats were collected at Playa Totoralillo, approximately $10 \mathrm{~km}$ south of Coquimbo $\left(30^{\circ} 04^{\prime} \mathrm{S}, 71^{\circ} 22^{\prime} \mathrm{W}\right)$, where mussels occur in dense patches (Thiel and Ullrich, 2002). Purple mussels from soft-bottom habitats were studied on tidal flats near Pelluco to the south-east of Puerto Montt $\left(41^{\circ} 29^{\prime} \mathrm{S}\right.$, $72^{\circ} 52^{\prime} \mathrm{W}$, Fig. 1b), where purple mussels form scattered beds together with $M$. edulis (Buschbaum et al., 2009). Blue mussels from hard-bottom habitats were studied in Concarneau (France) $\left(47^{\circ} 52^{\prime} \mathrm{N}, 03^{\circ} 53^{\prime} \mathrm{E}\right.$, Fig. 1c). Blue mussels from soft-bottom habitats were studied on tidal flats near the island of Sylt $\left(55^{\circ} 02^{\prime} \mathrm{N}, 08^{\circ} 06^{\prime} \mathrm{E}\right)$ in the northern Wadden Sea (eastern North Sea) (see Fig. 1d), where they form extensive beds (Reise, 1985, Kochmann et al., 2008, Buschbaum et al., 2009; for more detailed descriptions of the study sites, see Supplementary Material S1).

\subsection{Attachment strength of mussels in the field}

At the four study sites, we measured the attachment strength of randomly selected individual mussels (i.e. no specific choice was made during the investigations) using a spring balance. We fastened a laboratory clamp to a mussel, and using a plastic hook we pulled perpendicularly to the substratum with the spring balance until the mussel was detached from the substratum. Occasionally some of the randomly selected mussels were deeply immersed in the bed matrix and the clamp could not be firmly attached; in those cases, a small hole (i.e. about $1 \mathrm{~mm}$ wide) was made in the accessible section of the mussel shell through which a hook was inserted, which had no observable effect on the mussel response. Measurements where entire mussel clumps of several individuals were detached from the mussel bed were not considered, as herein we were interested in the attachment strength of individual mussels; these cases were rare and limited to mussels from soft-bottom habitats. 


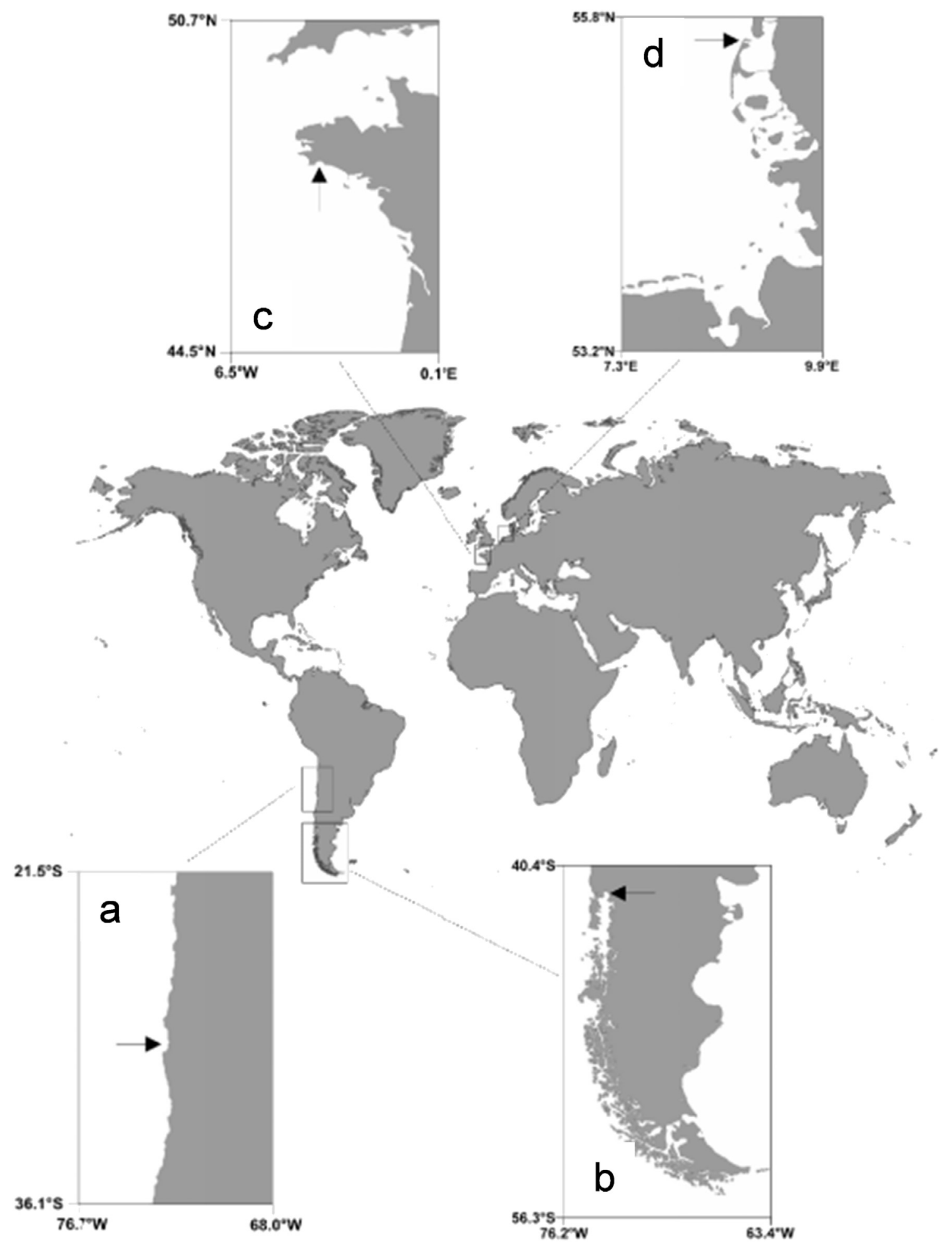

Fig. 1. Map depicting the different locations where studies were conducted in (A).

Concarneau (France), (B) Sylt (Germany), (C) Totoralillo (Chile), and (D) Pelluco (Chile). Arrows indicate the specific location where the samples and studies were conducted.

Attachment strength (i.e. force required for dislodgement) of mussels was measured to the nearest 0.1 Newton, and after detachment the body length of all mussels was measured to the nearest $0.1 \mathrm{~mm}$ with a caliper. We estimated attachment strength of 200 individuals of each species for each habitat type (Table 1a). For attachment strength measurements, we considered the effect of mussel position (edge and center) and of barnacle epibionts (clean and fouled). We measured attachment strength of 50 clean and 50 fouled (at least $50 \%$ shell coverage; estimated visually) mussels from the center, and of 50 clean and 50 fouled individuals from the edge of the mussel bed (see Table 1a). Thus, we evaluated the interactive effect of these variables (position and epibiont presence) on the relationship between mussel shell size and attachment strength. 

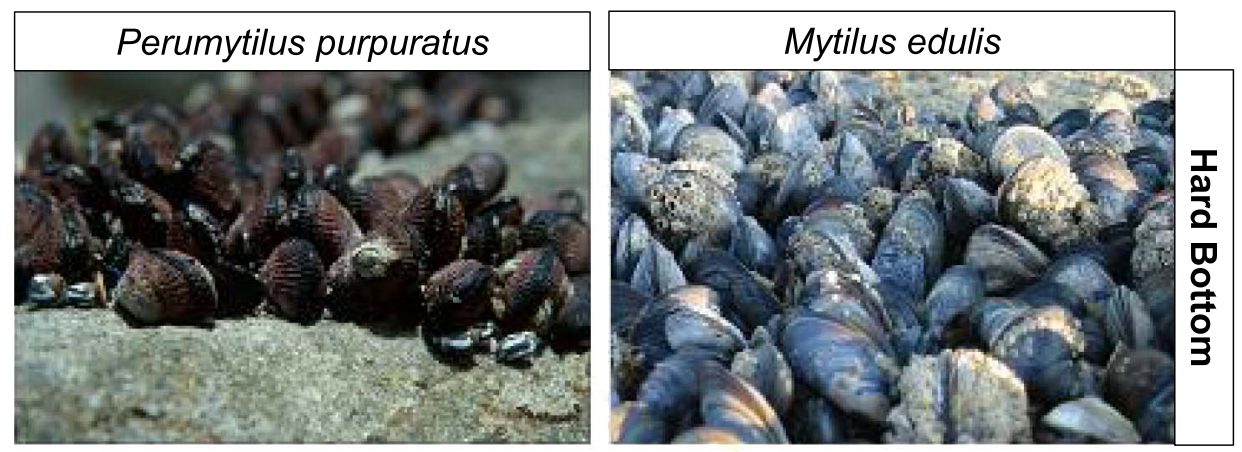

Fig. 2. General view of the focal species Perumytilus purpuratus and Mytilus edulis patches observed in both hard- and soft-bottom habitats.
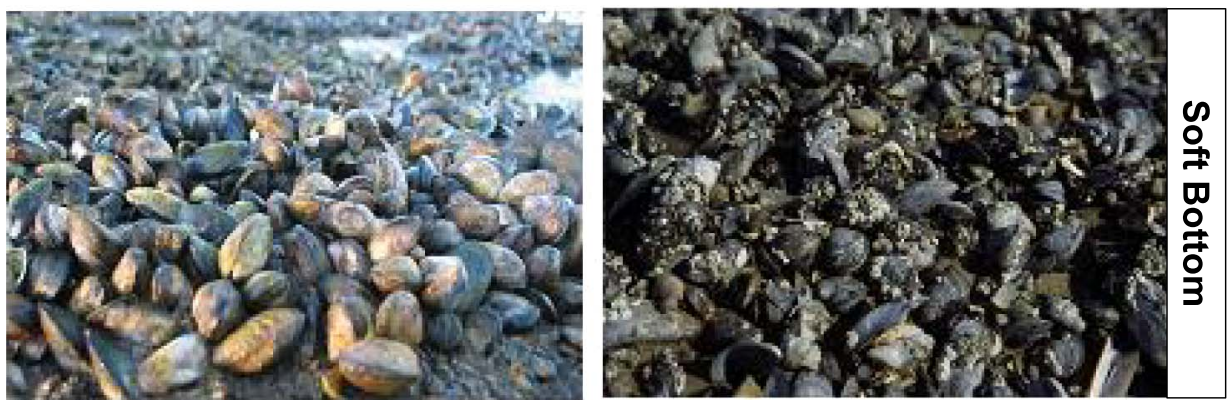

Table 1

Summary of the number of total mussel individuals used in different field and laboratory experiments conducted to estimate attachment strength and selective conspecific choice of the mussel Perumytilus purpuratus (Chile) and Mytilus edulis (Germany, France) in hardand soft-bottom habitats. "Position" in the attachment strength study, denote where individuals were found within the mussel matrix (i.e. in the edge or the center).

\begin{tabular}{|c|c|c|c|c|}
\hline & \multicolumn{2}{|c|}{ P. purpuratus } & \multicolumn{2}{|c|}{ M. edulis } \\
\hline & Hard & Soft & Hard & Soft \\
\hline \multicolumn{5}{|c|}{ a) Attachment strength } \\
\hline \multicolumn{5}{|c|}{ Position } \\
\hline Edge & 100 & 100 & 100 & 100 \\
\hline Center & 100 & 100 & 100 & 100 \\
\hline \multicolumn{5}{|l|}{ Condition } \\
\hline Clean & 50 & 50 & 50 & 50 \\
\hline Fouled & 50 & 50 & 50 & 50 \\
\hline \multicolumn{5}{|c|}{ b) Conspecific selective choice } \\
\hline \multicolumn{5}{|c|}{ Conspecific condition } \\
\hline Alive & 60 & 40 & 80 & 60 \\
\hline Dead & 60 & 40 & 80 & 60 \\
\hline Clean & 60 & 60 & 20 & 60 \\
\hline Fouled & 60 & 60 & 20 & 60 \\
\hline Firm & 60 & 40 & 54 & 45 \\
\hline Loose & 60 & 40 & 54 & 45 \\
\hline
\end{tabular}

\subsection{Selective byssus attachment behavior experiments}

In order to evaluate the ability of individual mussels $P$. purpuratus and $M$. edulis to selectively choose particular conspecifics for byssus attachment, we conducted laboratory experiments considering different conditions of individual mussels for attachment ("choice mussel") and the habitat where mussels were collected, i.e. soft and hard bottoms (see Table 1b).

\subsubsection{General protocol}

All experiments were conducted during the summer months (i.e. July-August in Germany and France, December-March in Chile). For each experiment, one focal individual was offered with a choice of two different conspecifics. The choice mussels were fixed to a plastic screen next to each other with plastic cable-ties, which ensured that these

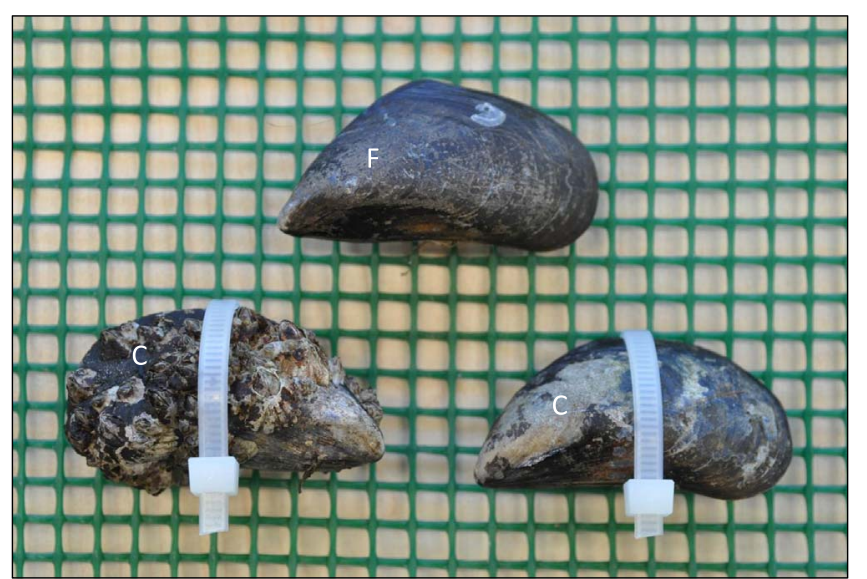

Fig. 3. Experimental set-up for the byssal attachment behavior experiments; focal mussel (F, Mytilus edulis in the photograph) was glued to a thread that was fixed to the plastic screen (green), and choice mussels (C; fouled versus clean in this picture) were held firmly closed with one cable-tie and with a second cable-tie attached to the screen. (For interpretation of the references to colour in this figure legend, the reader is referred to the web version of this article.)

individuals could not open during the experiment (Fig. 3). Each mussel was held closed with one cable-tie and attached to the screen with a 'connective' cable-tie. The objective of holding the choice mussels closed was to avoid that they could place byssal threads on the focal mussel. We used underwater cement to glue a thin thread to the focal mussel, which was then tied to the screen in a way that it was held in place near the choice mussels but was laying loose on the screen (Fig. 3). The objective of holding the focal mussel on a leash was to ensure that it was kept within reach of the choice mussels while allowing it to move freely and choose between the offered mussels. The two mussels offered as attachment substratum were placed at equal distance ( $\sim$ half body length) from the focal mussel. Both focal and choice mussels were collected in the field and transferred to the laboratory where they were immediately fastened to the plastic screen to start the experiment. During the experiment, mussels were held in large laboratory tanks with flowing seawater, which was continuously 
pumped from the natural environment. After $24 \mathrm{~h}$ we counted how many byssal threads the focal mussel had attached to the choice mussels. We also recorded the number of byssal threads placed on the plastic screen surface. For each mussel species and habitat, we considered three different and independent combinations of choice mussels:

- Dead versus alive: In order to examine whether focal mussels are able to distinguish and choose between dead and living mussels we offered empty shells and live mussels. Mussels were collected and separated randomly in two groups. Mussels from one group were opened and the flesh was removed carefully, thoroughly cleaning the interior of the shells, such that only the two shell valves remained. Empty valves were closed as to mimic a living mussel and clamped with a cable tie to the screen at the side of a living mussel that was attached to the screen in the same way.

- Clean versus fouled: In order to examine whether focal mussels are able to distinguish and choose between clean and fouled mussels, we offered clean mussels together with mussels that were heavily overgrown with barnacles (shell coverage of at least 50\%) from the respective study sites where balanids are the most frequent mussel epibionts (see Buschbaum et al., 2009; Valdivia et al., 2014). During collection of the choice mussels we attempted to find overgrown and clean mussels, but for M. edulis at Sylt and Concarneau, it was difficult to find completely clean mussels. In this case, we searched for mussels that had only few barnacles (shell coverage less than 10\%), which we carefully removed before the experiment.

- Loose versus firmly attached: In order to examine whether focal mussels are able to distinguish and choose between loose and firmly attached mussels we offered mussels loosely attached to the screen together with mussels firmly fixed to the screen. Herein we only used clean mussels. The connective cable-tie was either closed completely in order to hold the mussel firmly attached to the screen or it was not completely fixed in order to leave this choice mussel relatively loose.

For each choice mussel condition considered, 40 to 60 focal mussels were used for the experiments (see Table 1b). Exceptionally, we used 80 focal mussels for dead/alive experiments and 20 individuals for clean/ fouled experiments in Concarneau for M. edulis (see Table 1b). Each experiment was conducted independently and separately for $P$. purpuratus and $M$. edulis. In each assay, we counted the number of byssal threads produced by the different focal mussels on the different choice mussels offered.

\subsection{Data analyses}

We examined, separately for each species, the relationship between mussel shell size and attachment force, incorporating the effect of position (edge, center) and condition (fouled, clean) in this relationship. The relationship was tested with an Analysis of Covariance (ANCOVA) with mussel shell size as covariate, and matrix position (edge vs. center), epibiont presence (clean vs. fouled), and an interaction term as explanatory variables, and attachment strength as response variable. Previous to all analyses, we checked for homogeneity of variance through visual analysis of residuals, and independence of covariate and the explanatory variables, i.e. homogeneity of regression slopes. Analyses were conducted with the libraries "car", "compute.es", and "Effects" in the R-environment (R Development Core Team, R, 2014).

For the byssus selective attachment behavior experiments, we evaluated the total number of byssal threads produced by each focal mussel on the two choice-mussels and the experimental substratum (plastic screen) for both species and habitats. While this measure does not provide direct estimation of mussel selective choice, it provides information about the total byssus production of each focal mussel in the experimental conditions. We then also examined whether focal mussels had a specific preference (i.e. selective choice behavior) for one of the two choice mussels offered, determining the choice mussel to which each focal mussel had attached most byssal threads. For analyses, we first generated independent contingency tables on the total proportion of choice mussels onto which the focal mussel placed more byssal threads for each "choice-mussel" experiment (i.e. "alive" versus "dead", "fouled" versus "clean", and "loosely" versus "firmly" attached). Thus, for each focal species (P. purpuratus and M. edulis) and each habitat type (soft and hard bottom), separately, we evaluated the selection of conspecific "choice-mussel". In all cases, we considered the total of individuals used in each assay for analyses. Independence was tested with Pearson's Chi-square statistic $(\alpha=0.05)$ using the library MASS in the R-environment ( $R$ Development Core Team, R, 2014).

\section{Results}

\subsection{Attachment strength of mussels}

The relationship between mussel attachment strength and shell size was variable for both species $P$. purpuratus and $M$. edulis, in terms of epibionts and position of individual mussels from hard- and soft-bottom habitats (Fig. 2). This is represented in the low variance explained by the linear models (ANCOVA), which considered these variables for both species and habitats (see Table 2). For P. purpuratus from the hardbottom habitat, about $30 \%$ of the variance was explained by the linear model including barnacle epibionts (fouled, clean), position (edge, center), an interaction term, and the covariate (mussel shell size) (Table 2a). In contrast, for $P$. purpuratus from the soft-bottom habitat, the variance explained by the linear model was less than $10 \%$ (Table 2a).

In general, there was a positive relationship between shell size and attachment strength for $P$. purpuratus on hard-bottom habitats while for soft-bottom mussels the overall regression slope was slightly negative (ANCOVA; Table 2a). For M. edulis from the hard-bottom habitat, we also observed a positive relationship between shell size and attachment strength (ANCOVA; Table 2b) while for the soft-bottom habitat we detected no effect of mussel size on attachment strength for this species (see Regression Coefficients for ANCOVA in Table 2b).

Barnacle epibionts (fouled, clean) and position (edge, center) of the mussels had variable effects on the relationship between attachment force and shell size (Fig. 4). In the case of $P$. purpuratus, we found that the effect of shell size on attachment strength was lower in mussels from the edge in both hard- and soft-bottom habitats (i.e. the regression slope of the model is lower than for mussels from the center, see Table 2a and Fig. 4). No consistent pattern was observed for fouled individuals of $P$. purpuratus in both the soft- and hard-bottom habitat (Fig. 4), even though there was a statistically significant effect in the linear model for the soft-bottom habitat (Table 2a). For M. edulis, we observed that only the interaction between edge position and fouling was significant and positive in the regression but only for mussels in the soft-bottom habitat (Fig. 4, Table 2b). This suggests that large and fouled blue mussels from the edge of the mussel bed had higher attachment strength.

\subsection{Selective byssus attachment behavior experiments}

In general, attachment choices varied between mussel species and habitats. Perumytilus purpuratus individuals from hard-bottom habitats preferentially attached byssus on living choice mussels rather than on dead individuals (Fig. 5a, Table 3). Perumytilus purpuratus from the softbottom habitat also preferred living over dead individuals for attachment (Fig. 5c, Table 3). While P. purpuratus preferred "fouled" (with epibionts) over "clean" conspecifics in both hard- and soft-bottom habitats (Fig. 5a and c), there were no significant effects (Table 3). Perumytilus purpuratus from hard-bottom habitats tended to prefer loose over firm conspecifics but differences were not significant (Table 3), 
Table 2

Analyses of Covariance (ANCOVA, type III) on attachment strength (force to dislodgement) measured on hard- and soft-bottom habitats for the mussel species (a) P. purpuratus, and (b) $M$. edulis. Summary tables of the regression analyses and multiple regression coefficients are also shown. Significant values $(\alpha=0.05)$ are presented in bold.

a) Perumytilus purpuratus

\begin{tabular}{|c|c|c|c|c|}
\hline \multicolumn{5}{|l|}{ Hard } \\
\hline SV & df & SS & $\mathrm{F}$ & $P$ \\
\hline Covariate (size) & 1 & 1564 & 31.45 & $1.3 \times 10^{-7}$ \\
\hline Position (edge, center) (P) & 1 & 1778 & 35.8 & $1.27 \times 10^{-6}$ \\
\hline Condition $_{\text {(fouled, clean) }}(\mathrm{C})$ & 1 & 126.3 & 2.54 & 0.061 \\
\hline $\mathrm{P} \times \mathrm{C}$ & 1 & 57.6 & 1.159 & 0.283 \\
\hline \multirow[t]{2}{*}{ Residual } & 196 & 9738.9 & & \\
\hline & Estimate & Std. error & $t$-Value & $\mathrm{P}$ \\
\hline (Intercept) & 4.919 & 3.891 & 1.26 & 0.293 \\
\hline Covariate (size) & 0.863 & 0.157 & 5.48 & $1.3 \times 10^{-7}$ \\
\hline Position_edge & -7.206 & 1.441 & -5.00 & $1.27 \times 10^{-6}$ \\
\hline Condition_fouled & -2.672 & 1.417 & -1.89 & 0.061 \\
\hline Edge $\times$ fouled & 2.152 & 1.998 & 1.08 & 0.283 \\
\hline $\mathrm{R}^{2}$ & 0.318 & & & $1.6 \times 10^{-15}$ \\
\hline \multicolumn{5}{|l|}{ Soft } \\
\hline SV & df & SS & $\mathrm{F}$ & $P$ \\
\hline Covariate (size) & 1 & 74.41 & 6.11 & 0.0139 \\
\hline Position (edge, center) $(\mathrm{P})$ & 1 & 18.33 & 11.46 & 0.0319 \\
\hline Condition $_{\text {(fouled, clean) }}(\mathrm{C})$ & 1 & 45.21 & 11.45 & 0.0008 \\
\hline $\mathrm{P} \times \mathrm{C}$ & 1 & 5.15 & 4.64 & 0.2540 \\
\hline \multirow[t]{2}{*}{ Residual } & 303 & 119.6 & 1.31 & \\
\hline & Estimate & Std. error & $t$-Value & $P$ \\
\hline (Intercept) & 5.264 & 1.212 & 4.34 & $1.92 \times 10^{-5}$ \\
\hline Covariate (size) & -0.099 & 0.040 & -2.47 & 0.0139 \\
\hline Position_edge & -0.599 & 0.278 & -2.15 & 0.0008 \\
\hline Condition_fouled & -1.155 & 0.341 & -3.38 & 0.0319 \\
\hline Edge $\times$ fouled & 0.552 & 0.483 & 1.14 & 0.2541 \\
\hline $\mathrm{R}^{2}$ & 0.078 & & & 0.0005 \\
\hline
\end{tabular}

\begin{tabular}{|c|c|c|c|c|}
\hline \multicolumn{5}{|l|}{ b) Mytilus edulis } \\
\hline \multicolumn{5}{|l|}{ Hard } \\
\hline SV & df & SS & $\mathrm{F}$ & $\mathrm{P}$ \\
\hline Covariate (size) & 1 & 290.9 & 7.41 & 0.007 \\
\hline Position (P) & 1 & 86.2 & 2.19 & 0.139 \\
\hline Condition (C) & 1 & 16.3 & 0.41 & 0.520 \\
\hline $\mathrm{P} \times \mathrm{C}$ & 1 & 6.9 & 0.18 & 0.674 \\
\hline \multirow[t]{2}{*}{ Residual } & 195 & 7651.6 & & \\
\hline & Estimate & Std. error & $t$-Value & $\mathrm{P}$ \\
\hline (Intercept) & 6.019 & 4.524 & 1.33 & 0.785 \\
\hline Covariate (size) & 0.345 & 0.127 & 2.72 & 0.007 \\
\hline Position_edge & 1.858 & 1.253 & 1.48 & 0.139 \\
\hline Condition_fouled & -0.806 & 1.252 & -0.64 & 0.520 \\
\hline Edge $\times$ fouled & -0.745 & 1.772 & -0.42 & 0.674 \\
\hline $\mathrm{R}^{2}$ & 0.057 & & & 0.010 \\
\hline \multicolumn{5}{|l|}{ Soft } \\
\hline SV & $\mathrm{df}$ & SS & $\mathrm{F}$ & $\mathrm{P}$ \\
\hline Covariate (size) & 1 & 4.60 & 0.257 & 0.613 \\
\hline Position & 1 & 18.7 & 1.050 & 0.307 \\
\hline Condition & 1 & 57.1 & 3.208 & 0.075 \\
\hline $\mathrm{P} \times \mathrm{C}$ & 1 & 118.9 & 6.687 & 0.010 \\
\hline \multirow[t]{2}{*}{ Residual } & 195 & 3467.5 & & \\
\hline & Estimate & Std error & t-value & $\mathrm{P}$ \\
\hline (Intercept) & 7.514 & 4.079 & 1.84 & 0.067 \\
\hline Covariate (size) & 0.035 & 0.068 & 0.51 & 0.613 \\
\hline Position_edge & -0.926 & 0.903 & -1.03 & 0.307 \\
\hline Condition_fouled & 1.513 & 0.844 & 1.79 & 0.075 \\
\hline Edge $\times$ fouled & 3.196 & 1.236 & 2.59 & 0.010 \\
\hline $\mathrm{R}^{2}$ & 0.161 & & & $6.1 \times 10^{-7}$ \\
\hline
\end{tabular}

which could be related to higher number of the total of individual $(\sim 46$ cases) with no byssus production. The reversed pattern was found for purple mussels from soft-bottom habitats, which showed a statistically significant preference for firmly attached conspecifics (Fig. 5a and c, Table 3).

For hard- and soft-bottom M. edulis, we found no preference of the focal mussels for either alive or dead conspecifics (see Fig. 5b and d,
Table 3). There was a preference of "fouled" versus "clean" choice mussels for individuals from hard-bottoms, but differences were not significant. This pattern was not found for soft-bottom $M$. edulis, which showed no difference in preference for "fouled" or "clean" conspecifics (Fig. 5b and d, Table 3). Even though more M. edulis preferred the "firm" over the "loose" choice mussels from both hard and soft bottoms (Fig. 5b and c), no significant differences were observed in the analyses (Table 3).

Total byssus produced by the focal mussel in the "choice-mussel" experiments (i.e. the sum of byssus placed onto both choice-mussels and on the experimental substratum) differed among the independent attachment behavior experiments for both mytilid species (Fig. 6). Perumytilus purpuratus from the soft-bottom habitat tended to produce more total byssus than those from the hard-bottom habitat, although a clear trend was only observed for the "clean/fouled" experiment (Fig. 6a). For M. edulis we found a reverse pattern, with individuals from the hard-bottom habitat producing on average more byssus threads compared with individuals from the soft-bottom habitat for all the experiments conducted (Fig. 6b).

\section{Discussion}

Our results reveal that attachment strength increased with mussel size in hard-bottom habitats, which was a common pattern for both mussel species. Furthermore, our study on the attachment patterns and selective behavior of two mytilid mussels in both hard- and soft-bottom environments indicated that intraspecific interactions reflect evolutionary adaptations of both species to the respective coastal habitat. Total byssus production in the selection behavior experiments was comparatively higher in soft-bottom than in hard-bottom mussels for $P$. purpuratus, which contrasts with the pattern observed for M. edulis in which mussels from the hard-bottom habitat produced more byssus. Regardless of the source habitat, $P$. purpuratus preferred living over dead conspecifics for byssus attachment while selection for living conspecifics was less marked in M. edulis (and see summary Table 4). These results suggest species-specific adaptations of mussels, which correspond to particular habitat requirements ( $P$. purpuratus to hard bottoms; $M$. edulis to both soft and hard bottoms). In the context of these results, it is known that the variety of habitats and the distributional area where a species is able to establish persisting populations is a complex expression of its life history traits and evolutionary history (Brown, 1995). Our findings suggest that mytilid mussels are able to adjust byssus production (i.e. number and/or thickness) and attachment according to the available attachment substratum. Below, we discuss the mechanisms determining species-specific patterns and consequences for species' successful adaptation to different environments.

\subsection{Attachment strength depends on mussel traits and habitat}

The results of our study confirmed that attachment strength increased with mussel size for $P$. purpuratus and $M$. edulis inhabiting hardbottom habitats. Many other studies had shown that the risk of mussel dislodgment increases with water flow speed and mussel size (e.g., Hunt and Scheibling, 2001; Kirk et al., 2007; Denny and Gaylord, 2010) and decreases with mussel attachment strength to the substratum (e.g., Carrington, 2002b; Carrington et al., 2008). In addition, we found that position in the mussel matrix and epibiont load are also important factors influencing attachment strength.

Herein, we hypothesized that "edge"-positioned mussels could be detached more easily compared with "center"-positioned ones, given that the former have fewer conspecifics for mutual byssus attachment. This pattern was confirmed for $P$. purpuratus, because large and "edge"positioned purple mussels were more easily detached in both hard- and soft-bottom habitats. In contrast, wa Kangeri et al. (2014) had suggested that attachment strength is higher in edge-positioned mussels than in those from the center of the matrix, due to vulnerability for 


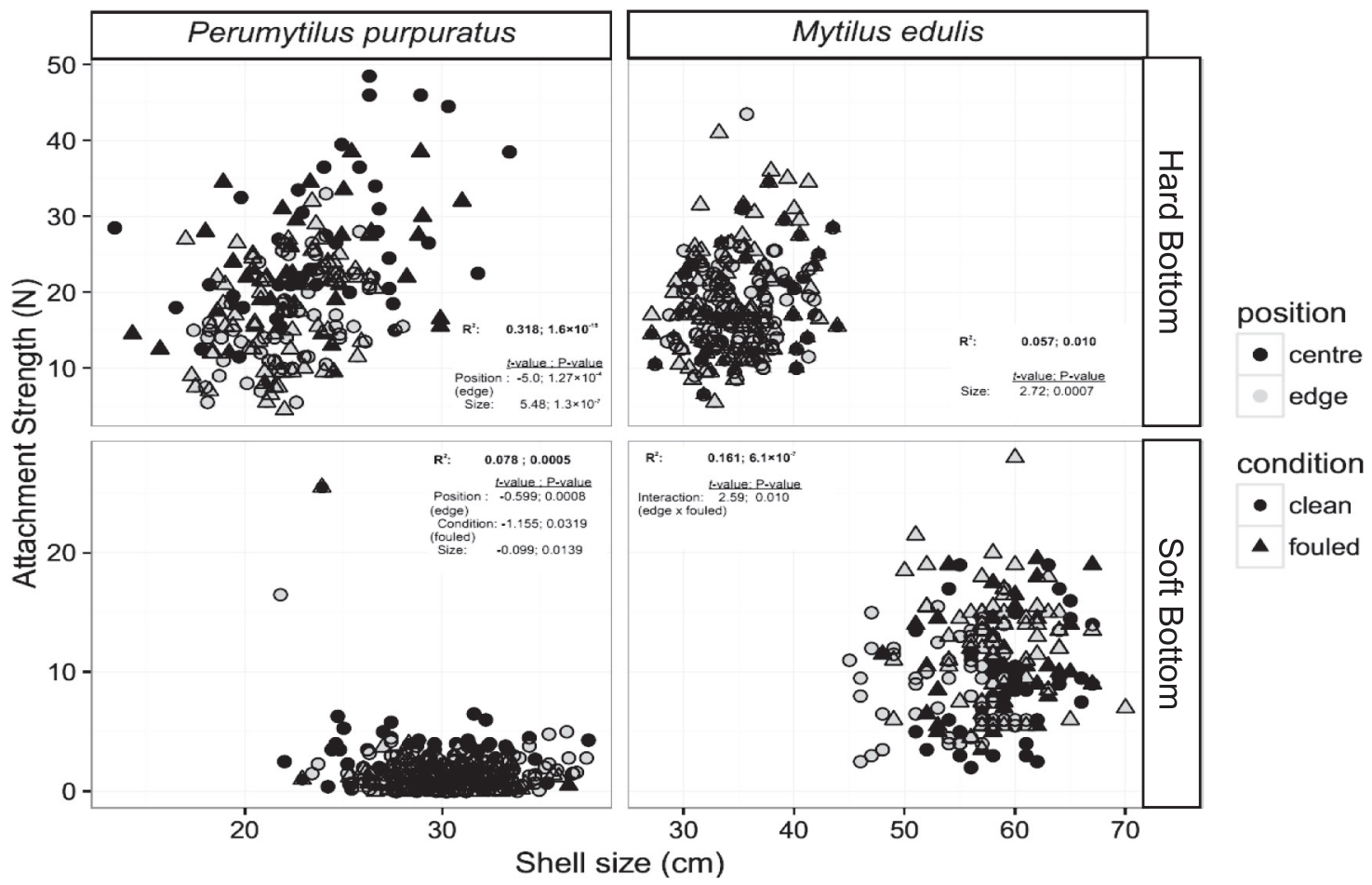

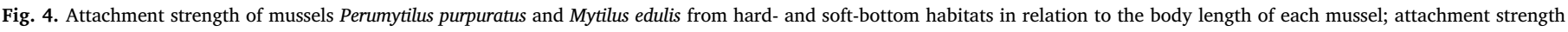

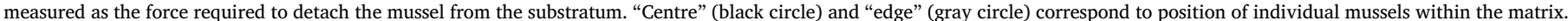

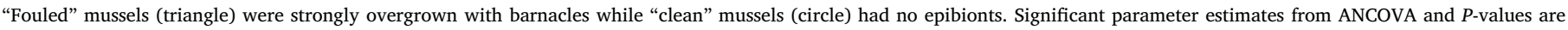
presented, respectively; for further details see Materials and methods section.

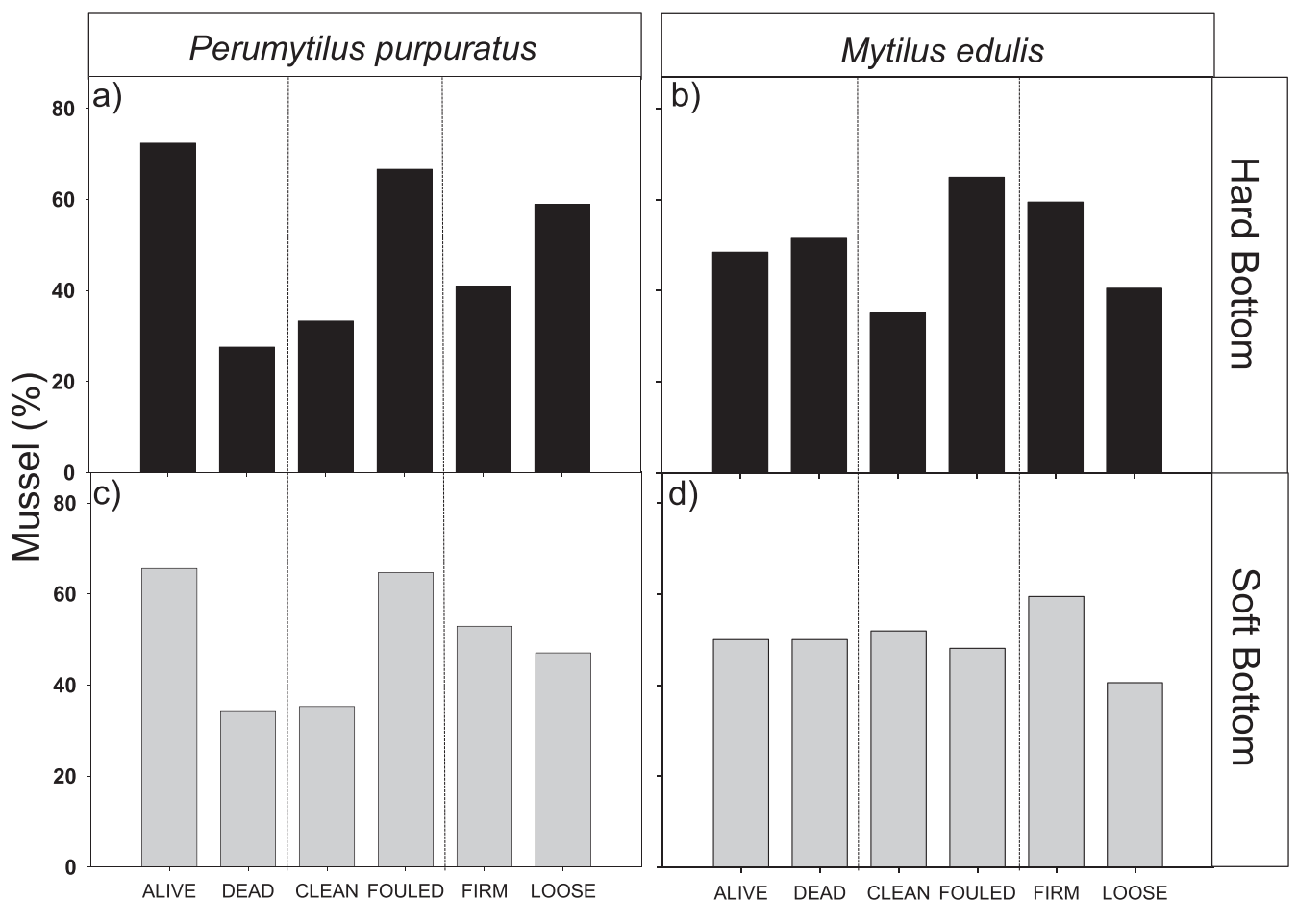

\section{Choice mussel condition}

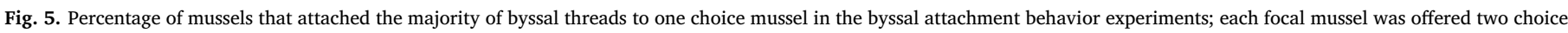
mussels and the number of byssal threads attached to the choice mussels was counted after an exposure time of $24 \mathrm{~h}$; for further details see Materials and methods section. 
Table 3

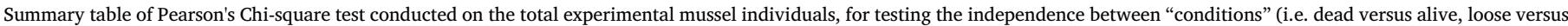

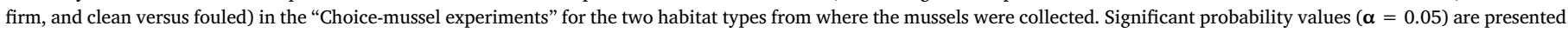
in bold.

\begin{tabular}{|c|c|c|c|c|c|c|c|c|}
\hline \multirow[t]{3}{*}{ Conspecific condition } & \multicolumn{4}{|c|}{ Perumytilus purpuratus } & \multicolumn{4}{|c|}{ Mytilus edulis } \\
\hline & \multicolumn{2}{|l|}{ Hard } & \multicolumn{2}{|l|}{ Soft } & \multicolumn{2}{|l|}{ Hard } & \multicolumn{2}{|l|}{ Soft } \\
\hline & $\chi^{2}$ & $\mathrm{P}$ & $\chi^{2}$ & $\mathrm{P}$ & $\chi^{2}$ & $\mathrm{P}$ & $\chi^{2}$ & $\mathrm{P}$ \\
\hline Alive/dead & 9.943 & 0.0016 & 4.133 & 0.0420 & 1.027 & 0.3108 & 0.0415 & 0.8385 \\
\hline Clean/fouled & 1.769 & 0.1836 & 0.9710 & 0.3245 & 0.125 & 0.7231 & 0.243 & 0.6223 \\
\hline Firm/loose & 1.800 & 0.1797 & 2.1202 & 0.0453 & 1.968 & 0.1608 & 2.519 & 0.1125 \\
\hline
\end{tabular}

a) Perumytilus purpuratus

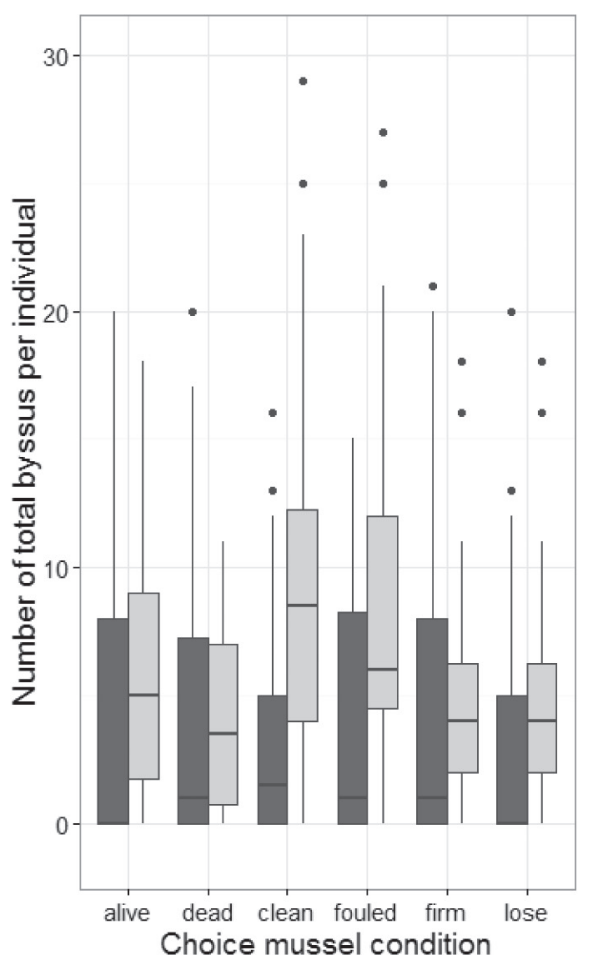

b) Mytilus edulis

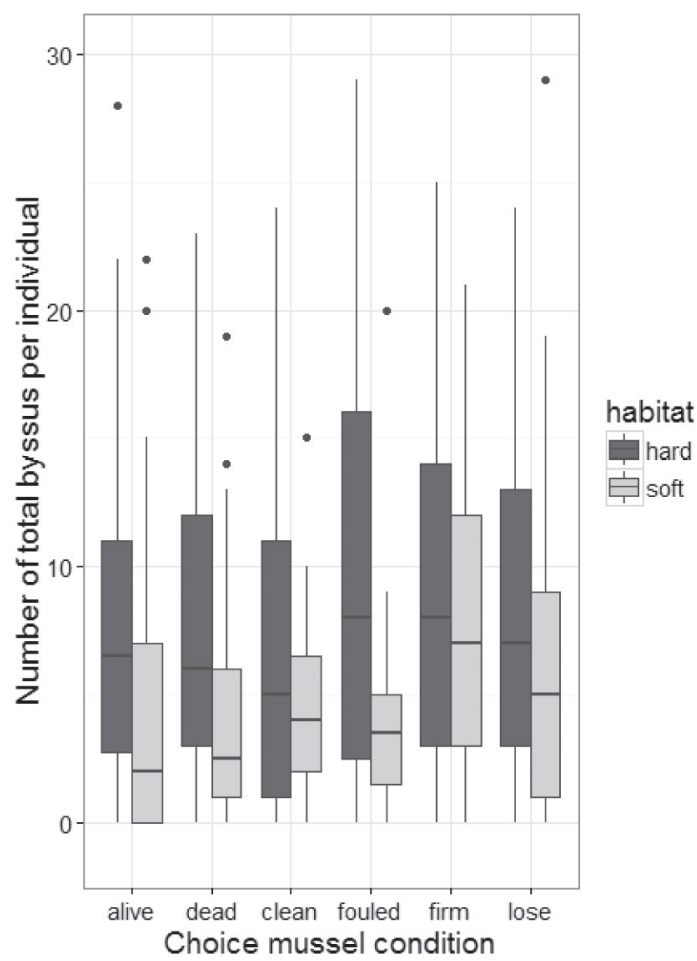

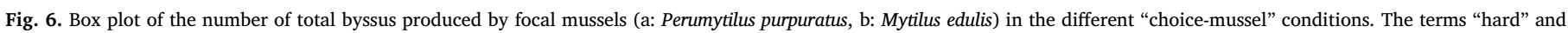

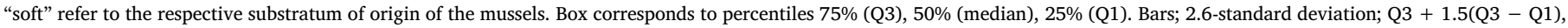
Q1 - 1.5(Q3 - Q1).

dislodgement caused by hydrodynamic forces such as waves. In partial agreement with wa Kangeri et al. (2014), herein we observed for $M$. edulis from soft-bottom habitats that large, fouled and edge-positioned mussels tended to have higher attachment strength. Higher attachment in edge-positioned individuals of $M$. edulis can have important consequences to reduce complete mussel bed erosion caused by hydrodynamic forces (wa Kangeri et al., 2016), a phenomenon still not examined in $P$. purpuratus.

Our results confirmed the importance of epibionts for attachment strength. Possibly, mussels with epibionts are more exposed to strong

Table 4

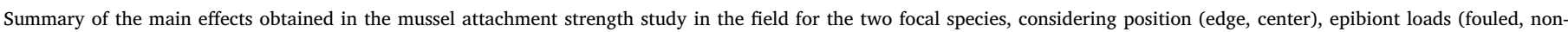

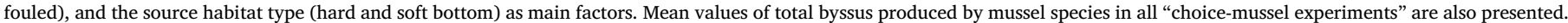
$(+)$ : positive effect on attachment strength, $(-)$ : negative effect, (0): no significant effect.

\begin{tabular}{|c|c|c|c|c|}
\hline Habitat & Position_Edge & Epibionts & Shell size & Total byssus production (mean $\pm \mathrm{SE}$ ) \\
\hline \multicolumn{5}{|c|}{ Perumytilus purpuratus } \\
\hline Hard & $(-)$ & $(0)$ & $(+)$ & $3.8( \pm 0.27)$ \\
\hline Soft & $(-)$ & $(-)$ & $(0)$ & $7.11( \pm 0.32)$ \\
\hline \multicolumn{5}{|c|}{ Mytilus edulis } \\
\hline Hard & $(0)$ & $(0)$ & $(+)$ & $8.23( \pm 0.38)$ \\
\hline Soft & $(+)^{\mathrm{a}}$ & $(+)^{\mathrm{a}}$ & $(+)^{a}$ & $5.62( \pm 0.30)$ \\
\hline
\end{tabular}

${ }^{\mathrm{a}}$ Denotes interactive effect of factors. 
hydrodynamic stress (i.e. those positioned at the edge of the matrix) and need to invest much energy in byssus production, which could explain the higher attachment strength of "fouled" and "edge"-positioned $M$. edulis from the soft-bottom habitat in our study (i.e. the significant fouled $\times$ edge interaction term). Witman and Suchanek (1984) also showed that mussels overgrown with algae are more strongly attached to the substratum, probably to prevent dislodgement due to higher flow resistance. In contrast to M. edulis, we found evidence that barnacle epibiont load on $P$. purpuratus leads to reduced attachment strength in the soft-bottom habitat (see summary Table 4), although mussels from this habitat produced more byssus threads in the byssus attachment behavior experiments (Fig. 6). Since $P$. purpuratus more regularly occurs in hard-bottom habitats where it is strongly attached to the substratum (Thiel and Ullrich, 2002; Prado and Castilla, 2006), this species may invest more byssus production in soft-bottom environments in trying to achieve similar attachment strength as on rocky shores (see Bell and Gosline, 1997; Carrington et al., 2008; Salas et al., 2015). The same pattern of higher byssus production in softbottom habitats has been observed for the mussel Brachidontes rodriguezii, which attach to coarse sediment available (Salas et al., 2015). Even though sediment grain size is relatively coarse $(\sim 0.6-0.8 \mathrm{~mm}$ in diameter) in the soft-bottom habitat at one of the study sites at Pelluco in southern Chile, these sediment particles are much too small for $P$. purpuratus to provide suitable attachment substratum reducing the risk of hydrodynamic dislodgement. Thus, higher and selective (i.e. conspecific attachment) byssus production is expected in this habitat. Higher byssus production (i.e. number of byssus thread), however, might not compensate for the low availability of primary attachment substratum. In the same context, byssus thickness could also confer higher attachment to mussels in soft-bottom habitats independent of the number of byssal threads produced by individuals in this environment (Carrington et al., 2015). However, since we did not quantify byssus thickness in our study we can only speculate in this context. Thus, future studies should examine the relationship between number of byssus produced and its quality (e.g. thickness), which are key traits determining mussel ability to remain attached under intense hydrodynamic stress (Carrington et al., 2015).

\subsection{Selective conspecific attachment behavior}

Our results showed that $P$. purpuratus preferred living over dead conspecifics, which reveals that mussels are capable of distinguishing between mussels of different attachment quality. Mussels might detect specific mechanical (e.g. heart beat) or chemical cues related to living or dead conspecifics for attachment selection (e.g. Kobak, 2001; Khalaman and Lezin, 2015).

Given that in our study mussel species from hard-bottom habitats showed no or only weak selection for "firm" versus "loose" conspecifics, possibly due to low sample size for mussels from hard-bottom habitats, it is likely that conspecific choice behavior is triggered by more specific cues. Indeed, mussels are known to react to chemical cues released from attachment substratum (e.g. Pansch et al., 2009), predators (e.g. Côte, 1995; Reimer and Tedengren, 1997; Kobak et al., 2010), or injured conspecifics, which is a strategy to reduce mortality risk (e.g., Caro et al., 2008; Cheung et al., 2009; Garner and Litvaitis, 2013). Thus, it is possible that mussels avoided dead shells in our experiments because of chemical cues that remained within the empty shells after removing the flesh just before starting the experiments. This is in line with previous studies, which showed that mussels can recognize damaged conspecifics, and react by increased production of byssus (Cheung et al., 2009). In this context, studies by Khalaman and Lezin (2015) showed similar preferential attachment behavior of blue mussels to animal ('living') surfaces compared to inert material suggesting that this species can discriminate living organisms from inanimate objects.

Previous studies conducted in soft-bottom habitats (e.g., Buschbaum, 2000, 2001) had shown that the absence of primary attachment substratum (i.e. low predictability for attachment) forces individuals to attach almost exclusively to conspecifics, and thus a stronger selectivity in conspecific attachment is expected (Selin and Vekhova, 2004). Hence, selective conspecific choice could enhance the probability of survival in less predictable habitats. For example, studies by Young (1983a) showed low conspecific selectivity in blue mussels from hard substrata, but they suggested that selectivity should increase in sedimentary areas (Young, 1983b). Therefore, it was surprising that a selection for living conspecifics was less marked in M. edulis in our experiments in soft-bottoms. Despite the missing selectivity for living individuals, $M$. edulis reaches comparatively high attachment strength within the mussel bed matrix in sedimentary environments (Fig. 4). This finding suggests that also other factors such as the total network structure of the byssus threads produced by many mussels in a conglomerate could be of higher importance for M. edulis bed stability than the selection behavior of single mussels for living conspecifics and this should be studied in forthcoming investigations.

Given that "fouled" $P$. purpuratus from the soft-bottom habitat showed lower attachment strength, selective choice of "clean" versus "fouled" conspecifics would be advantageous in this habitat, but this was not observed in the attachment experiments. This suggests that selection for clean over fouled conspecifics is a trait not incorporated in $P$. purpuratus populations, which would be advantageous for this species to successfully adapt to less predictable habitats. This coincides with studies showing higher byssus production as an advantageous strategy for stressful habitats (i.e. higher predator pressure; Selin and Vekhova, 2004; Garner and Litvaitis, 2013; water current or strong wave action; e.g., Bell and Gosline, 1997; Carrington et al., 2008; and Carrington et al., 2015).

In general, our study showed that in mytilid mussels selection for particular conspecifics might be a common response, which ensures survival in less predictable habitats. Other studies have related differences in byssus production and attachment strength of mussels on soft versus hard surfaces to particular morphological adaptations (Mytilus coruscus versus Modiolus modiolus; Selin and Vekhova, 2004), and to environmental stressors such as light gradients (e.g. Dreissena polymorpha; Kobak, 2001). However, these traits are also significantly affected by selective choice of mussels (Lezin and Khalaman, 2007; Khalaman and Lezin, 2015; this study). Conspecific and interspecific selectivity have been attributed to competition (Khalaman and Lezin, 2015), and to predator presence (Côte, 1995; Reimer and Tedengren, 1997; Lezin and Khalaman, 2007). Thus, conspecific selection seems to have a role for coexistence with diverse species comprising the benthic community, and could also be important for the mussels' potential to colonize novel (i.e. natural or artificial) habitats.

\subsection{Concluding remarks}

As suggested by our results, in addition to previous studies, attachment strength of mussels within a bed matrix seems to be influenced by the interactive effect of mussel size, position in the mussel matrix, epibiont load, and substratum choice for attachment. We found that the preferential byssus attachment to specific conspecific is a plastic trait in different mytilid mussel populations. Its occurrence can be driven by effective conspecific cues and habitat type, because habitat properties seem to influence byssus production and attachment choices of mussels. Thus, all these attributes/strategies may be important for mussels to achieve successful adaptation to less predictable (i.e. higher detachment risk) habitats. These attributes can also have consequences for persistence of mussel bed structure (e.g. Paine and Levin, 1981; wa Kangeri et al., 2014), and therefore, also indirectly affect the function of a mussel bed as an important habitat for a highly diverse community of associated species (Thiel and Ullrich, 2002; Prado and Castilla, 2006).

Our study thus highlights the importance of determining the role of conspecific choices in the adaptation of habitat-forming species like mussels to novel and stressful habitats. These behavioral traits may not 
only determine the persistence of mussel beds in different habitats, but also their resistance to invaders (Buschbaum et al., 2016) or their own invasion success as shown in the Mediterranean mytilid mussel $M$. galloprovincialis (Branch and Steffani, 2004).

Supplementary data to this article can be found online at http://dx. doi.org/10.1016/j.jembe.2017.09.009.

\section{Acknowledgements}

During this project we received support in the form of an ECSA travel grant (MT), institutional funds (CB) and BMBF/CONICYT exchange program \#2001-182 (CB, MT). We are grateful to A. Zander who supported us during some of the experiments in Chile, Germany and France. M.A. Aguilera was financed by FONDECYT grant \#1160223 and PAI-CONICYT \#79150002 during the writing of the manuscript. We are also very grateful to Sergey Dobretsov, two anonymous reviewers and the editor for helpful suggestions on the manuscript, as well as to Alice Monk and Eike Petersen for language support.

\section{References}

Alvarado, J.L., Castilla, J.C., 1996. Tridimensional matrices of mussels Perumytilus purpuratus on intertidal platforms with varying wave forces in central Chile. Mar. Ecol. Prog. Ser. 133, 135-141.

Babarro, J.M.F., Carrington, E., 2013. Attachment strength of the mussel Mytilus galloprovincialis: effect of habitat and body size. J. Exp. Mar. Biol. Ecol. 443, 188-196.

Bell, E.C., Gosline, J.M., 1997. Strategies for life in flow: tenacity, morphometry, and probability of dislodgement of two Mytilus species. Mar. Ecol. Prog. Ser. 159, 197-208.

Berkman, P., Haltuch, M., Tichich, E., Garton, D., Kennedy, G., Gannon, J., Mackey, S., Fuller, J., Liebenthal, D., 1998. Zebra mussels invade lake Erie muds. Nature 393, $27-28$.

Branch, G.M., Steffani, C.N., 2004. Can we predict the effects of alien species? A casehistory of the invasion of South Africa by Mytilus galloprovincialis (Lamarck). J. Exp. Mar. Biol. Ecol. 300, 189-215.

Brown, J.H., 1995. Macroecology. University of Chicago Press, Chicago.

Buschbaum, C., 2000. Direct and indirect effects of Littorina littorea (L.) on barnacles growing on mussel beds in the Wadden Sea. Hydrobiologia 440, 119-128.

Buschbaum, C., 2001. Selective settlement of the barnacle Semibalanus balanoides (L.) facilitates its growth and reproduction on mussel beds in the Wadden Sea. Helgol. Mar. Res. 55, 128-134.

Buschbaum, C., Saier, B., 2001. Growth of the mussel Mytilus edulis L. in the Wadden Sea affected by tidal emergence and barnacle epibionts. J. Sea Res. 45, 27-36.

Buschbaum, C., Dittmann, S., Hong, J.-S., Hwang, I.-S., Strasser, M., Thiel, M., Valdivia, N., Yoon, S.-P., Reise, K., 2009. Mytilid mussels: global habitat engineers in coastal sediments. Helgol. Mar. Res. 63, 47-58.

Buschbaum, C., Cornelius, A., Goedknegt, M.A., 2016. Deeply hidden inside introduced biogenic structures - pacific oyster reefs reduce detrimental barnacle overgrowth on native blue mussels. J. Sea Res. 117, 20-26.

Caro, A.U., Escobar, J., Bozinovic, F., Navarrete, S.A., Castilla, J.C., 2008. Phenotypic variability in byssus thread production of intertidal mussels induced by predators with different feeding strategies. Mar. Ecol. Prog. Ser. 127, 127-134.

Carrington, E., 2002a. Seasonal variation in the attachment strength of blue mussels: causes and consequences. Limnol. Oceanogr. 47, 1723-1733.

Carrington, E., 2002b. The ecomechanics of mussel attachment: from molecules to ecosystems. Integr. Comp. Biol. 42, 846-852.

Carrington, E., Moeser, G.M., Thompson, S.B., Coutts, L.C., Craig, C.A., 2008. Mussel attachment on rocky shores: the effect of flow on byssus production. Integr. Comp. Biol. 48, 801-807.

Carrington, E., Moeser, G.M., Dimond, J., Mello, J.J., Boller, M.L., 2009. Seasonal disturbance to mussel beds: field test of a mechanistic model predicting wave dislodgment. Limnol. Oceanogr. 54, 978-986.

Carrington, E., Waite, H.J., Sará, J., Sebens, K.P., 2015. Mussels as a model system for integrative ecomechanics. Annu. Rev. Mar. Sci. 7, 443-469.

Cheung, S.G., Yang, F.Y., Chiu, J.M.Y., Liu, C.C., Shin, P.K.S., 2009. Anti-predator behaviour in the green-lipped mussel Perna viridis: byssus thread production depends on the mussel's position in clump. Mar. Ecol. Prog. Ser. 378, 145-151.

Côte, I.M., 1995. Effects of predatory crab influents on byssus production in mussels. J. Exp. Mar. Biol. Ecol. 188, 233-241.

Denny, M.W., Gaylord, B., 2010. Marine ecomechanics. Annu. Rev. Mar. Sci. 2, 89-114.

Garner, Y.L., Litvaitis, M.K., 2013. Effects of wave exposure, temperature and epibiont fouling on byssal thread production and growth in the blue mussel, Mytilus edulis, in the Gulf of Maine. J. Exp. Mar. Biol. Ecol. 446, 52-56.

Guiñez, R., Pita, A., Pérez, M., Briones, C., Navarrete, S.A., Toro, J., Presa, P., 2016. Present-day connectivity of historical stocks of the ecosystem engineer Perumytilus purpuratus along $4500 \mathrm{~km}$ of the Chilean Coast. Fish. Res. 179, 322-332.
Gutiérrez, J.L., Jones, C.G., Strayer, D.L., Iribarne, O.O., 2003. Mollusks as ecosystem engineers: the role of shell production in aquatic habitats. Oikos 101, 79-90.

Harley, C.D.G., 2008. Tidal dynamic, topographic orientation, and temperature-mediated mass mortalities on rocky shores. Mar. Ecol. Prog. Ser. 371, 37-46.

Helmuth, B., Mieszkowska, N., Moore, P., Hawkins, S.J., 2006. Living on the edge of two changing worlds: forecasting the responses of rocky intertidal ecosystems to Climate Change. Annu. Rev. Ecol. Evol. Syst. 37, 373-404.

Hunt, H., Scheibling, R.E., 2001. Predicting wave dislodgement of mussels: variation in attachment strength with body size, habitat, and season. Mar. Ecol. Prog. Ser. 213, 157-164.

wa Kangeri, A.K., Jansen, J.M., Barkman, B.R., Donker, J., Joppe, D.J., Dankers, N.M.J.A., 2014. Perturbation induced changes in substrate use by the blue mussel, Mytilus edulis, in sedimentary systems. J. Sea Res. 85, 233-240.

wa Kangeri, A.K., Jansen, J.M., Joppe, D.J., Dankers, N.M.J.A., 2016. In situ investigation of the effects of current velocity on sedimentary mussel bed stability. J. Exp. Mar. Biol. Ecol. 485, 65-72.

Khalaman, V.V., Lezin, P.A., 2015. Clumping behavior and byssus production as strategies for substrate competition in Mytilus edulis. Invertebr. Biol. 134, 38-47.

Kirk, M., Esler, D., Boyd, S.W., 2007. Morphology and density of mussels on natural and aquaculture structure habitats: implications for sea duck predators. Mar. Ecol. Prog. Ser. 346, 179-187.

Kobak, J., 2001. Light, gravity and conspecific as cues to site selection and attachment behaviour of juvenile and adult Dreissena polymorpha Pallas 1771. J. Molluscan Stud. 67, 183-189.

Kobak, J., Kakareko, T., Poznańska, M., 2010. Changes in attachment strength and aggregation of zebra mussel, Dreissena polymorpha in the presence of potential fish predators of various species and size. Hydrobiologia 644, 195-206.

Kochmann, J., Buschbaum, C., Volkenborn, N., Reise, K., 2008. Shift from native mussels to alien oysters: differential effects of ecosystem engineers. J. Exp. Mar. Biol. Ecol. $364,1-10$.

Laudien, J., Wahl, M., 1999. Indirect effects of epibiosis on host mortality: seastar predation on differently fouled mussels. Mar. Ecol. 20, 35-47.

Levin, S., Paine, R.T., 1974. Disturbance, patch formation, and community structure. PNAS 71, 2744-2747.

Lezin, P.A., Khalaman, V.V., 2007. Byssus production rate of the White Sea blue musse Mytilus edulis (Linnaeus, 1758) in the presence of metabolites of some hydrobionts. Russ. J. Mar. Biol. 33, 58-60.

Molen, S. van der, Márquez, F., Idaszkin, Y.L., Adami, M., 2012. Use of shell-shape to discriminate between Brachidontes rodriguezii and Brachidontes purpuratus species (Mytilidae) in the transition zone of their distributions (south-western Atlantic). J. Mar. Biol. Assoc. UK 93, 803-808.

Okamura, B., 1986a. Formation and disruption of aggregations of Mytilus edulis in the fouling community of San Francisco Bay, California. Mar. Ecol. Prog. Ser. 30, 275-282.

Okamura, B., 1986b. Group living and the effects of spatial position in aggregations of Mytilus edulis. Oecologia 69, 341-347.

Paine, R.T., Levin, S.A., 1981. Intertidal landscapes: disturbance and the dynamics of pattern. Ecol. Monogr. 51, 145-178.

Pansch, C., Cerda, O., Lenz, M., Wahl, M., Thiel, M., 2009. Consequences of light reduction for anti-herbivore defense and bioactivity against mussels in four seaweed species from northern-central Chile. Mar. Ecol. Prog. Ser. 381, 83-97.

Prado, L., Castilla, J.C., 2006. The bioengineer Perumytilus purpuratus (Mollusca: Bivalvia) in central Chile: biodiversity, habitat structural complexity and environmental heterogeneity. J. Mar. Biol. Assoc. UK 86, 417-421.

R Development Core Team, R, 2014. R: a language and environment for statistical computing. In: R Found. Stat. Comput.

Reimer, O., Tedengren, M., 1997. Predator-induced changes in byssal attachment, aggregation and migration in the blue mussel, Mytilus edulis. Mar. Freshw. Behav. Physiol. 30, 251-266.

Reise, K., 1985. Tidal flat ecology. In: Ecological Studies 54. Springer Verlag, Berlin, pp. $1-191$.

Salas, M.C., Defeo, O., Narvarte, M., 2015. Attachment features of mytilids in ecosystems with mobile substrate: Brachidontes rodriguezii in San Antonio Bay (Patagonia, Argentina). J. Mar. Biol. Assoc. UK 98, 1449-1456.

Selin, N.I., Vekhova, E.E., 2004. Effects of environmental factors on byssal thread formation in some members of the family Mytilidae from the Sea of Japan. Russ. J. Mar. Biol. 30, 306-313.

Thiel, M., Ullrich, N., 2002. Hard rock versus soft bottom: the fauna associated with intertidal mussel beds on hard bottoms along the coast of Chile, and considerations on the functional role of mussel beds. Helgol. Mar. Res. 56, 21-30.

Valdivia, N., Buschbaum, C., Thiel, M., 2014. Succession in intertidal mussel bed assemblages on different shores: species mobility matters. Mar. Ecol. Prog. Ser. 497, $131-142$.

Wethey, D.S., 2002. Biogeography, competition, and microclimate: the barnacle Chthamalus fragilis in New England. Integr. Comp. Biol. 42, 872-880.

Witman, J.D., Suchanek, T.H., 1984. Mussels in flow: drag and dislodgement by epizoans. Mar. Ecol. Prog. Ser. 16, 259-268.

Young, G.A., 1983a. Response to, and selection between, firm substrata by Mytilus edulis. J. Mar. Biol. Assoc. UK 63, 653-659.

Young, G.A., 1983b. The effect of sediment type upon the position and depth at which byssal attachment occurs in Mytilus edulis. J. Mar. Biol. Assoc. UK 63, 641-651. 